\title{
Monitoring the Effects of Slope Hazard Mitigation and Weather on Rockfall along a Colorado Highway Using Terrestrial Laser Scanning
}

\author{
Luke Weidner* and Gabriel Walton
}

Citation: Weidner, L.; Walton, G Monitoring the Effects of Slope Hazard Mitigation and Weather on Rockfall along a Colorado Highway Using Terrestrial Laser Scanning. Remote Sens. 2021, 13, 4584. https:// doi.org $/ 10.3390 /$ rs13224584

Academic Editors: Stephen Grebby and Stuart Marsh

Received: 16 September 2021 Accepted: 5 November 2021 Published: 15 November 2021

Publisher's Note: MDPI stays neutral with regard to jurisdictional claims in published maps and institutional affiliations.

Copyright: (c) 2021 by the authors. Licensee MDPI, Basel, Switzerland. This article is an open access article distributed under the terms and conditions of the Creative Commons Attribution (CC BY) license (https:// creativecommons.org/licenses/by/ $4.0 /)$.
Department of Geology and Geological Engineering, Colorado School of Mines, Golden, CO 80401, USA; gwalton@mines.edu

* Correspondence: weidner@mines.edu

\begin{abstract}
Rockfall is a frequent hazard in mountainous areas, but risks can be mitigated by the construction of protection structures and slope modification. In this study, two rock slopes along a highway in western Colorado were monitored monthly using Terrestrial Laser Scanning (TLS) before, during, and after mitigation activities were performed to observe the influence of construction and weather variables on rockfall activity. Between September 2020 and February 2021, the slopes were mechanically scaled and reinforced using rock bolts, wire mesh, and polyurethane resin injection. We used a state-of-the-art TLS monitoring workflow to process the acquired point clouds, including semiautomated algorithms for alignment, change detection, clustering, and rockfall-volume calculation. Our initial hypotheses were that the slope-construction activities would have an immediate effect on the rockfall rate post-construction and would exhibit a decreased correlation with weatherrelated triggering factors, such as precipitation and freeze-thaw cycles. However, our observations did not confirm this, and instead an increase in post-construction rockfall was recorded, with strong correlation to weather-related triggering factors. While this does not suggest that the overall mitigation efforts were ineffective in reducing rockfall hazard and risk of large blocks, we did not find evidence that mitigation efforts influenced the rockfall hazard associated with the release of small- to medium-sized blocks $\left(<1 \mathrm{~m}^{3}\right)$. These results can be used to develop improved and tailored mitigation methods for rock slopes in the future.
\end{abstract}

Keywords: rockfall; mitigation; precipitation; triggering; scaling

\section{Introduction}

Rockfall is a common hazard in mountainous areas. Rockfall can damage homes or infrastructure, are costly to clean up, and present a low-frequency risk of injury or death. Because rockfall events often develop in a brittle fashion and without adequate warning [1], forecasting of individual failures is difficult, so the risk is often reduced in practice by the construction of permanent protection structures and/or excavation of the slope. Rockfall hazard mitigation may consist of the installation of various berms, catchment fences, bolts, or draped steel-mesh structures, as well as mechanical scaling and resloping, all with intention of reducing either the probability of rockfall occurrence or the probability of negative consequences from rockfall [2].

Measuring the change in rockfall probability in response to various external factors, such as human activity or construction, seasonal weather patterns and storms, or long-term climate change, is an active area of research [3-8]. For example, the effects of constructing retention fences or berms can be evaluated using numerical runout simulations, which inform the placement and size of structures to optimally reduce rockfall hazard $[9,10]$. Remote sensing is widely used in open-pit mining to assess slope stability and anticipate large failures, which minimizes production delays and improves the safety of workers [11,12]. Macciotta et al. [3] used a rockfall database and meteorological data to build a tool allowing 
railway operators to anticipate periods of high rockfall probability. High temporal and spatial resolution observations on rockfall occurrence and their consequences thus have the potential to allow us to make better informed decisions on how to mitigate rockfall risks.

Various methods have been proposed to quantify rockfall activity in a consistent and objective manner. Terrestrial laser scanning (TLS) and other remote-sensing techniques are increasingly used to characterize slope processes in high spatial and temporal detail [13-16]. In contrast with field observations of rockfall deposits or two-dimensional photography-based methods, TLS-based monitoring can provide much more accurate and direct information regarding the volume and source location of rockfalls $<0.01 \mathrm{~m}^{3}$, all the way up to slope failures $>10 \mathrm{~m}^{3}$. Further, open-source point cloud-processing algorithms have improved in the past few years, such that the creation of large digital rockfall databases is increasingly accessible and efficient [17-21].

While the use of TLS and related techniques to quantify rockfall rates is increasingly common and standardized [22], their use for the assessment of rock slope hazard-mitigation activities is mostly absent from the literature. For example, mechanical scaling, spot bolting, and grouting are often installed at the discretion of an engineer in the field based on expert judgement, but there is no widely available quantitative data on the long-term effectiveness of such approaches or how the effectiveness changes over time. Wyllie and Mah [2] state, for example, that minor scaling applied to a rock slope susceptible to weathering might have to be repeated every three to five years. They also suggest that if improperly conducted, scaling could further destabilize a slope or be ineffective if the rock is highly degradable or weathered. These observations raise the following questions regarding rockfall hazard mitigation: does the rockfall rate change after scaling and reinforcement of a rock slope? For how long does a scaled and reinforced rock slope along a highway exhibit a reduced rockfall rate? Does the rockfall rate stay reduced over the long-term, or does it eventually return to an equilibrium state of activity?

The current study contributes to answering these questions by using a state-of-theart, TLS, rockfall-monitoring workflow to observe two slopes subjected to mitigation activities, including scaling, bolting, grouting, and mesh installation. The activities were commissioned by the Colorado Department of Transportation and executed in Morrison, Colorado, from September 2020 to February 2021. TLS monitoring was conducted prior to the start of construction in April 2021 and continues to the present, with the intention of continuing for several years. This study focuses on observing rockfall patterns before and after mitigation construction, with the goal of quantitatively documenting the impact of the construction efforts on the rockfall hazard at the site.

\section{Materials and Methods}

\subsection{Study Sites and Data Collection}

In spring 2020, the authors were informed of the planned locations of rockfallmitigation activities in Bear Creek Canyon along Colorado State Highway 74 near the town of Morrison, Colorado, USA. Based on this, two sites, named Site E and Site HI, were selected for TLS monitoring, which commenced in April 2020 (Figure 1). Site E is close to $50 \mathrm{~m}$ in height, considerably taller than Site HI at $17 \mathrm{~m}$. Site E is located in a tight bend in the road and has a length of $70 \mathrm{~m}$, while Site HI follows a straightaway for about $240 \mathrm{~m}$. TLS monitoring was conducted at approximately one-month intervals at both sites using a FARO Focus x330 laser scanner along the opposite side of the two-lane highway. Figure 1 shows the location of both slopes in relation to the state of Colorado, as well as an illustration of the dates when scans were collected. Scans were collected at multiple positions at each site to ensure consistent coverage of the entire slope and minimize occlusions. Site E used three scan positions while Site HI used six positions. 
a)

c)

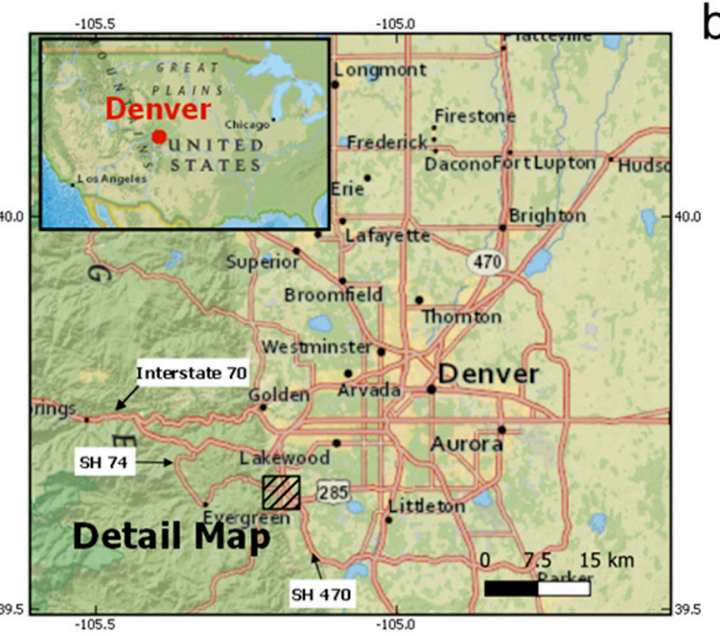

b)
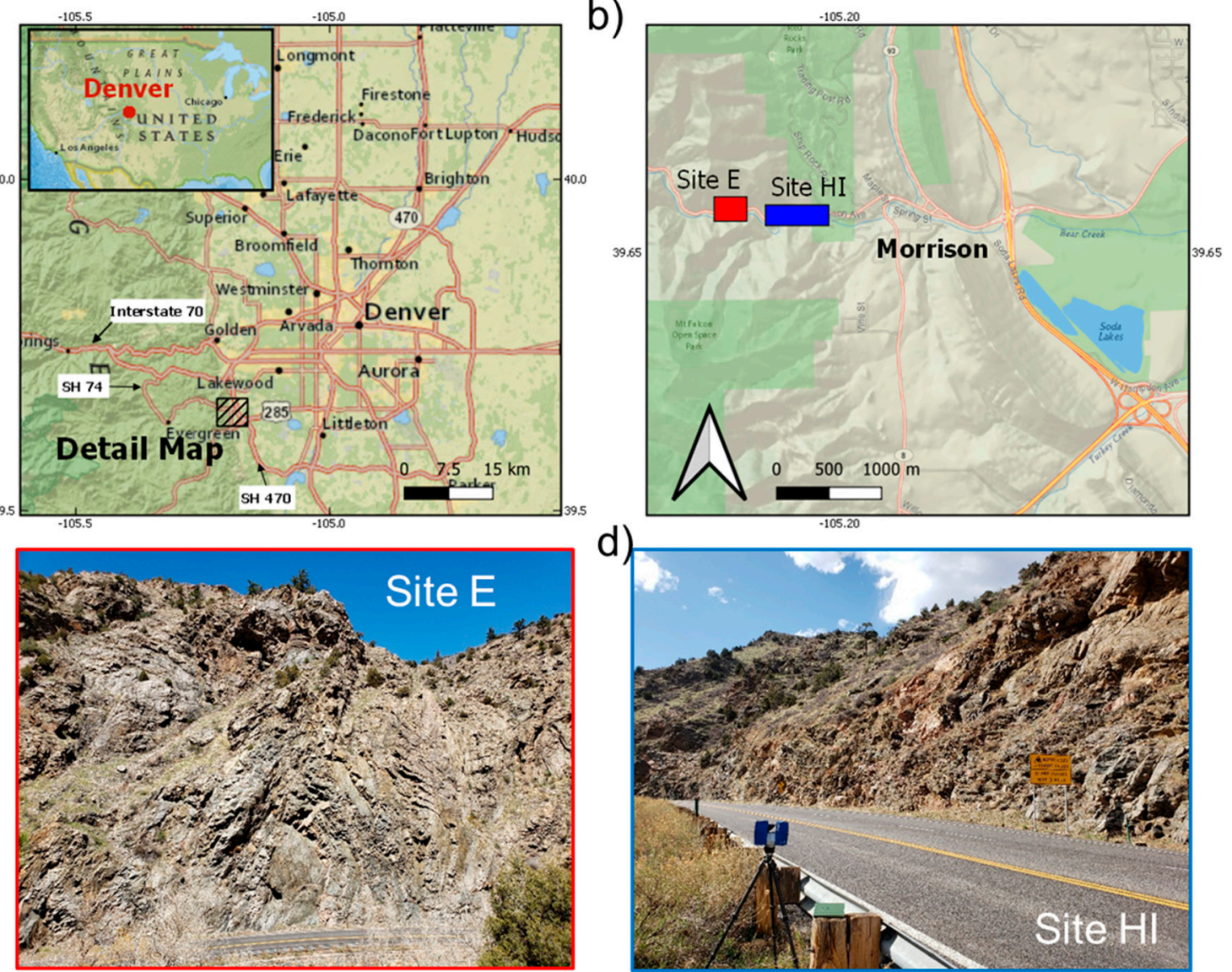

d)

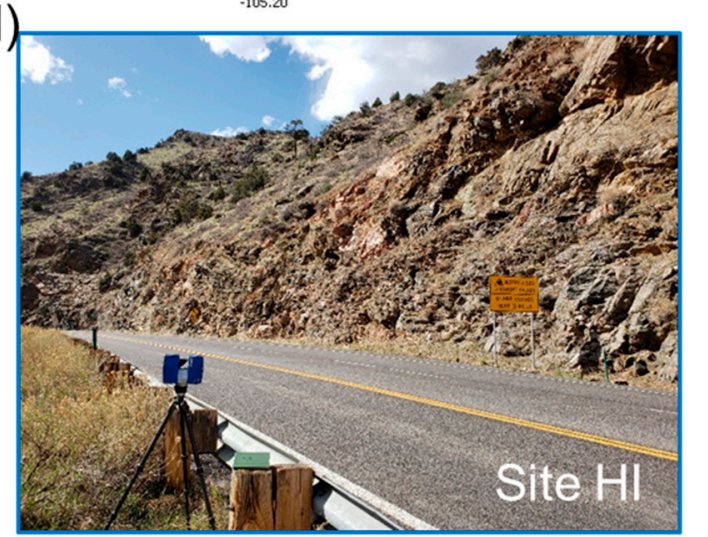

e)

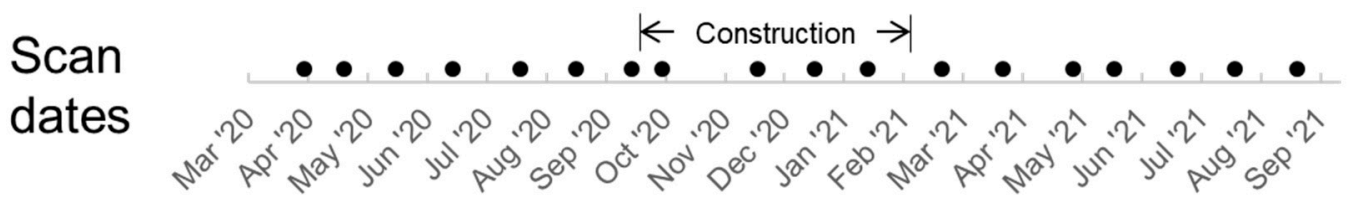

Figure 1. Illustration of the data-collection process for this study. Maps (a,b) show locations of two scanning sites in relation to the Denver, Colorado, area, with corresponding photographs for each site (c,d). The line plot (e) indicates the data-collection dates for both sites and the approximate period when construction was performed.

Both sites have slope angles of greater than 80 degrees and are considered high hazard due to their proximity to the road surface and limited visibility in the winding canyon. The sites are south-facing cut slopes, consisting of folded and granite-intruded gneiss with different degrees of weathering. The rockmass quality is influenced by the greater Colorado Front Range tectonic system, which has produced jointing and faulting throughout the region. At Site E, the rockmass is predominantly governed by a pair of orthogonal joint sets dipping between 65 and 80 degrees to the southeast and southwest with $2 \mathrm{~m}$ spacing, in addition to other more irregular surfaces formed by gneissic foliation. The rockmass quality at Site $\mathrm{E}$ is moderate with relatively low degrees of weathering and one groundwater seep location (Geological Strength Index (GSI) $=40$ to 60, see [23,24]). The rockmass at Site HI is more strongly fractured and weathered, with more ubiquitous jointing, foliation, and evidence of past deformation, including what was interpreted by the authors to be a $1 \mathrm{~m}$ wide fault zone on the east end of the site (slope GSI $=40$ to 50, fault zone GSI $=25$ to 35). 


\subsection{Weather Data}

To evaluate any possible correlations of rockfall occurrence with weather patterns during the scanning periods, basic weather metrics were extracted from a nearby weather station in Evergreen, Colorado (Global Historical Climatology Network ID: USC00052790), approximately $9 \mathrm{~km}$ from Site $\mathrm{E}$ and $9.5 \mathrm{~km}$ from Site HI. In addition to precipitation, temperature, and snowfall, we also evaluated freeze-thaw cycles from this data: a day was defined as having a freeze-thaw cycle if the maximum temperature was above freezing and the minimum temperature was below freezing [25].

\subsection{Rockfall Hazard Mitigation}

At Site E, rockfall-mitigation activities included rock scaling and clearing out of the narrow catchment ditch, injection of grout and polyurethane resin (PUR) at select locations, installation of wire mesh, and drilling of rock-reinforcement bolts (spot bolting). PUR has been increasingly used by the Colorado Department of Transportation as a cost-effective alternative to injection grouting for stabilizing a rockmass while also preserving the rock's natural surface appearance [26]. It was noted that wire mesh was only installed in the vicinity of a single protruding block located approximately $40 \mathrm{~m}$ up from the base of the slope and thus did not extend down the slope face to the road level. At Site HI, the activities were rock scaling, spot bolting, and clearing and enlargement of the rockfall-catchment ditch. In addition, at Site HI, the traffic pattern was modified to accommodate the removal of a second lane of westbound traffic, increasing the distance between the slope and the roadway and opening up room for the installation of a $1 \mathrm{~m}$ high concrete barrier.

\subsection{Point Cloud Data Processing}

Raw point clouds from each scanner position were processed to generate a single aligned scan for each site and each epoch, which were then compared to other aligned scans at different epochs to identify rockfalls and construction-related changes. We used recently developed semi-automated algorithms designed specifically for analysis of rock slope point clouds [21,27-29], as described in the following sections (Figure 2).

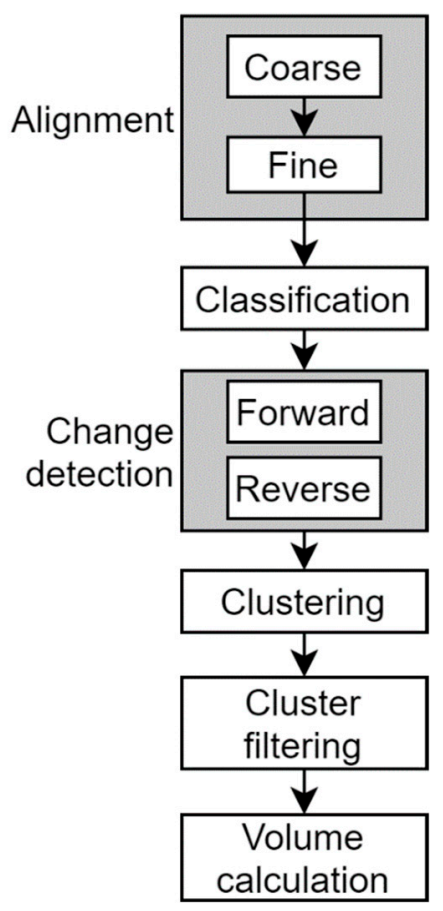

Figure 2. Workflow used to process TLS scans and calculate rockfall volumes. 


\subsubsection{Alignment}

The scan positions for each epoch must be merged into a single point cloud before comparison through time, since multiple scan positions were utilized at both sites. This was performed by first constructing a single "base" model, in which the individual scan positions in this model were aligned with each other internally. Then each individual scan position from all other epochs was aligned to the full base scan. For Site E, a single base scan from 7 April 2020 was used for the entire study period, but at Site HI, a second base scan for the post-construction period was created using data from January 2021 due to the large amount of slope change caused by scaling in fall 2020 at that site.

Alignment consisted of two steps: a coarse alignment and a fine alignment. Both steps were performed manually using CloudCompare [30] to visually confirm alignment quality at every step. The coarse alignment consisted of manually selecting corresponding point pairs in the two point clouds to align, and the fine alignment used an iterative closest point (ICP) algorithm to minimize the nearest neighbor distances between the two clouds. Since changes caused by rockfall are small relative to the size of the slope, they have a negligible effect on the alignment quality using ICP. This is a widely used procedure for rock slope point clouds $[20,21]$. Note that after the aligned individual scan positions for a given epoch were merged, the final point cloud was subsampled to a minimum point spacing of $1.5 \mathrm{~cm}$ to reduce file size while preserving all the relevant details of the surface.

\subsubsection{Classification}

Classification consists of removing regions of the point cloud not corresponding to rockfall source areas, such as vegetation, snow and ice, or grassy slopes and benches. This step can potentially take advantage of machine-learning-based computer vision algorithms for semantic segmentation [18,31]. However, Weidner et al. [18] showed that for rockfall studies on slopes without large translational failures, a single classification "mask" with areas of vegetation manually segmented out resulted in a similarly accurate classification as a machine-learning method. Further, due to statistical outlier filter steps incorporated into the code of Schovanec et al. [21], we observed that vegetation was mostly removed automatically without a dedicated classification step, and any remaining unwanted areas were filtered out in the final rockfall-filtering step described below. Therefore, the classification step was considered optional and was typically not performed except to improve visualization.

\subsubsection{Change Detection}

Change between two point clouds of natural scenes is commonly calculated using the multiscale model-to-model cloud comparison (M3C2) method [32]. M3C2 first estimates the local normal direction to the slope, then collects points in a cylinder around this normal vector. Finally, the distance between the centers of gravity of points in the two clouds are calculated. This results in change values that are robust to variations in local surface roughness and are more accurate in complex topography. We used the modified M3C2 version created by Schovanec et al. [21], which was made more robust for rock slopes by reducing the likelihood that the cylinder will intersect multiple surfaces.

The two parameters for this algorithm are the normal calculation radius and the cylinder radius. The choice of cylinder radius can significantly influence the level of detail captured in change results. DiFrancesco et al. [20] demonstrated a tradeoff between statistical confidence in results and the smallest rockfall that was able to be detected based on the selected radius. With a subsampled point spacing of $1.5 \mathrm{~cm}$, we selected a relatively large normal calculation radius of $20 \mathrm{~cm}$ and a cylinder radius of $10 \mathrm{~cm}$. These choices were deemed reasonable, as we were ultimately able to identify rockfall volumes as small as $0.0001 \mathrm{~m}^{3}$.

Alignment and change-detection quality were assessed by statistical analysis of the change values. In the absence of independent ground control points, we used the limit of detection (LoD) concept as a proxy for point cloud precision (which is influenced both by 
individual point precision and overall alignment quality). In the literature, limit of detection was often defined in terms of the spatially variable local roughness of the two clouds and a constant or spatially variable alignment error component [32,33]. For simplicity, we assumed that these components were spatially constant and chose worst-case, conservative values to define the LoD. We estimated $\mathrm{LoD}$ as $\pm 2 \mathrm{~s}$ of computed changes in stable areas of rock, roughly corresponding to a $95 \%$ confidence interval. The s term was estimated by fitting a normal distribution to the histogram of change values, and values of s typically varied between $0.004 \mathrm{~m}$ and $0.01 \mathrm{~m}$. As a result, we chose an upper bound value of $\pm 0.02 \mathrm{~m}$ as the LoD for all point clouds in this study. This value was deemed conservative enough to minimize the amount of erroneous change passing through to subsequent processing steps, but not too high as to incorrectly remove many small rockfalls.

For rockfall analysis, the change calculation described above was performed twice for each epoch: once in the forward time direction (Time 1 to Time 2) and once in the reverse time direction (Time 2 to Time 1). The goal of this procedure was to identify the points corresponding to the front and back faces of rockfalls. Change in the forward direction captured points corresponding to the front face of the rock block, while reverse change captured the back face. Points with change values below the LoD were removed in the forward and reverse change point clouds, then the two point clouds were merged, resulting in isolated regions of points corresponding to individual rockfall blocks (see [29] for more details on this step). However, all rockfalls were contained within a single point cloud object at this step. Clustering had to be performed to segment points corresponding to real rockfalls into individual clusters, which could then be operated on individually for volume calculation.

\subsubsection{Clustering and Cluster Filtering}

Clustering is commonly performed using an unsupervised clustering algorithm, with density-based spatial clustering of applications with noise (DBSCAN [34]) and its derivatives being the most common for rockfall analysis [35]. We used the implementation developed by Schovanec et al. [21], which was optimized for large point clouds. The inputs to this algorithm were the merged and filtered point cloud from the last step and two clustering parameters, Epsilon and MinPoints. Epsilon defines the search radius used to check if points belong in the same cluster or different clusters, and MinPoints defines the minimum number of points a cluster must have to be kept and not classified as noise. For this study, we used the same $10 \mathrm{~cm}$ Epsilon value as Schovanec et al. [21], which is appropriate for point clouds with high resolution (point spacing $<2 \mathrm{~cm}$ ), and a MinPoints value of 50 .

The output of the clustering step was around 100 to 800 small point cloud objects (clusters), each representing an individual cluster output from DBSCAN. The number of clusters varied for each epoch depending on the presence of snow, ice, and vegetation, as well as the overall rockfall activity on the slope. As a result, only around $5 \%$ to $30 \%$ of clusters corresponded to true rockfalls, with the rest being attributed to residual alignment error, vegetation, snow, ice, false change from complex topography with high local curvature, or occlusions. To calculate the volume of true rockfalls, the rockfall clusters had to be distinguished from erroneous change and non-rockfall change clusters. The most common approach to solving this problem and extracting only true rockfalls is to impose some basic filtering criteria, such as a minimum number of points and symmetry conditions for the front and back face of the cluster, combined with manual verification [20,29]. Other approaches involve calculating statistics for each cluster, such as the minimum and maximum change values and the lengths of the principal axes, then applying a machinelearning algorithm to classify each cluster as either a true rockfall or non-rockfall [21,36]. Schovanec et al. [21] showed that automated cluster filtering enabled a much more realistic estimate of the frequency-magnitude distribution of rockfalls with a classification error rate of less than $20 \%$. While these automated methods for rockfall classification are promising, at present, they still require some manual validation to ensure that large rockfalls are not 
misclassified. For the current study, we opted for a fully manual classification approach to ensure the highest possible accuracy, performing no automated filtering.

\subsubsection{Volume Calculation}

Once true rockfall clusters were identified, they passed through an algorithm that estimated the volume of individual rockfalls. At this step, only the $X, Y$, and $Z$ values of cluster points were used: $\mathrm{M} 3 \mathrm{C} 2$ change values were not required for volume calculation. The estimation of the volume of a rockfall cluster was challenging due to the unstructured and potentially noisy nature of the points. Most algorithms employ some form of a convex hull or Delaunay triangulation to create a closed mesh representation of the cluster from which the volume can be extracted. A generalization of the convex hull called an alphashape is commonly used for rockfall volume calculation, since it allows a degree of user control on the level of detail of the mesh $[17,37]$. The level of detail was controlled by the $\alpha$ parameter, where an alpha shape with $\alpha=\infty$ was equivalent to the convex hull.

The most difficult aspect of using the alpha-shape method was the selection of the $\alpha$ parameter, which had a large impact on the resulting volume of the mesh. This was because if the mesh was too simplified, the volume would have been greatly overestimated, while if the mesh was too detailed, it would fail to properly enclose all points and underestimate the volume. Bonneau et al. [17] developed an iterative algorithm to find the smallest $\alpha$ parameter that created a "watertight manifold surface mesh". This ensured the shape was not too simplified but also had no interior holes. In contrast, Schovanec et al. [21] used an empirical method to estimate the $\alpha$ parameter by testing a range of possible values and observing the resulting volumes. In preliminary tests comparing these two approaches, we found that both methods were acceptable for volume estimation, but the iterative hole-checking algorithm produced slightly larger volumes on average for larger rockfalls than the empirical method. We opted to use the Bonneau et al. [17] method directly for our analysis.

\section{Results}

\subsection{Construction Activities}

The TLS-monitoring campaign was able to develop a record of major steps of the construction process, including rock scaling and injection of PUR. Scaling was performed in September through November 2020 at both sites, while other activities, such as mesh installation and reinforcement drilling, continued until early February 2021. While pinned mesh was installed at Site E, it only covered the uppermost portion of the slope with poor visibility from the scanning positions and the wires were too small of a diameter to create strong reflections, so it was not analyzed in this study. Table 1 shows the approximate volumes of rock scaled for Sites E and HI, and Figures 3 and 4 illustrate the extent of scaling in the change-detection point clouds. In the period where construction took place, we assumed that all volume loss corresponded to scaling; note that this was reasonable given that rockfall rates are typically low during this season in Colorado [8]. It was evident that a much greater volume of material was removed at Site HI compared to Site E, even after accounting for the differences in size between the two sites.

Table 1. Summary of rock removed by mechanical scaling at Site E and Site HI.

\begin{tabular}{ccccc}
\hline Start Date & End Date & Rockfall Count & Volume $\left.\mathbf{( m}^{\mathbf{3}}\right)$ & Volume Per Unit Slope Area $\left(\mathbf{m}^{3} / \mathbf{m}^{\mathbf{2}}\right)$ \\
\hline 19 September 2020 & 4 October 2020 & 148 & 26.53 & $7.73 \times 10^{-3}$ \\
\hline 4 October 2020 & 21 November 2020 & 62 & 1.50 & $4.38 \times 10^{-4}$ \\
\hline & & Site HI & $8.16 \times 10^{-2}$ \\
\hline 4 October 2020 & 21 November 2020 & 815 & 334.43 & $1.90 \times 10^{-4}$ \\
\hline 21 November 2020 & 20 December 2020 & 109 & 0.78 & \\
\hline
\end{tabular}




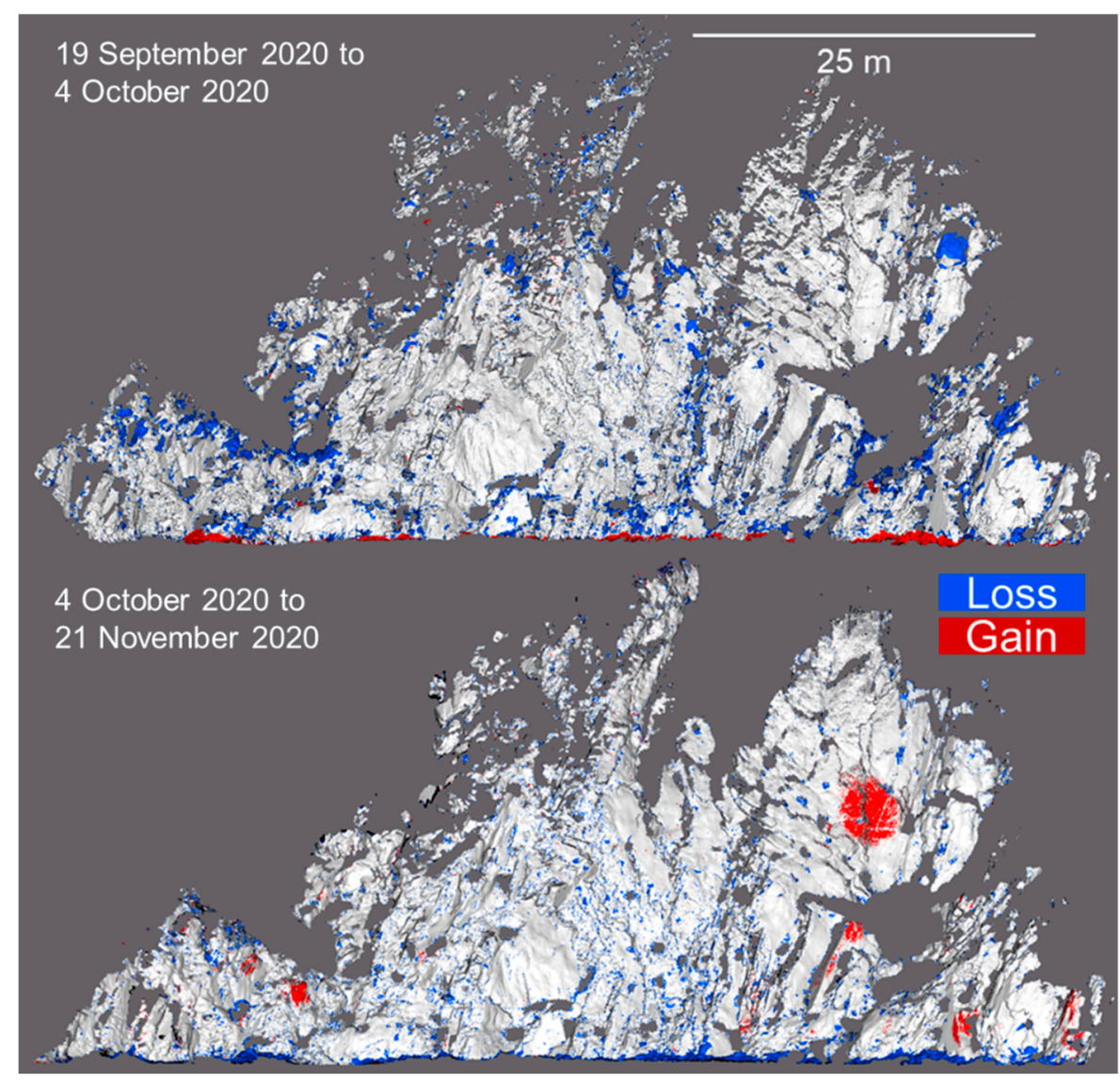

Figure 3. Point clouds for Site E showing the extent of mechanical scaling performed between September and November 2020. Gray points are those with change values less than $\pm 2 \mathrm{~cm}$.

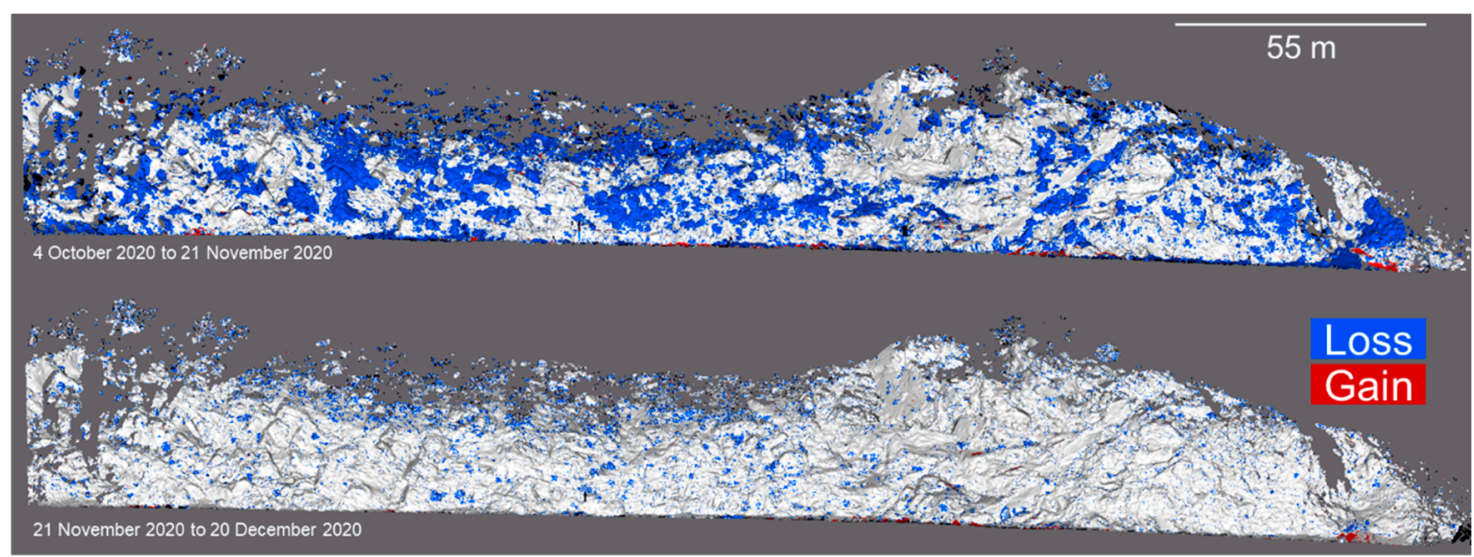

Figure 4. Point clouds for Site HI showing the extent of mechanical scaling performed between October and December 2020. Gray points are those with change values less than $\pm 2 \mathrm{~cm}$.

At Site E, we were also able to observe conspicuous outward deformations in the rockmass, which temporally corresponded to the drilling and injection of PUR boreholes (Figure 5). We interpreted these deformations as a response of the rockmass to the pressure exerted by solidifying PUR along interior joints and fractures. Deformations were highest near the assumed injection site, with magnitudes ranging from around $0.03 \mathrm{~m}$ to $0.05 \mathrm{~m}$. Deformations extended and decreased radially around each apparent central point. 


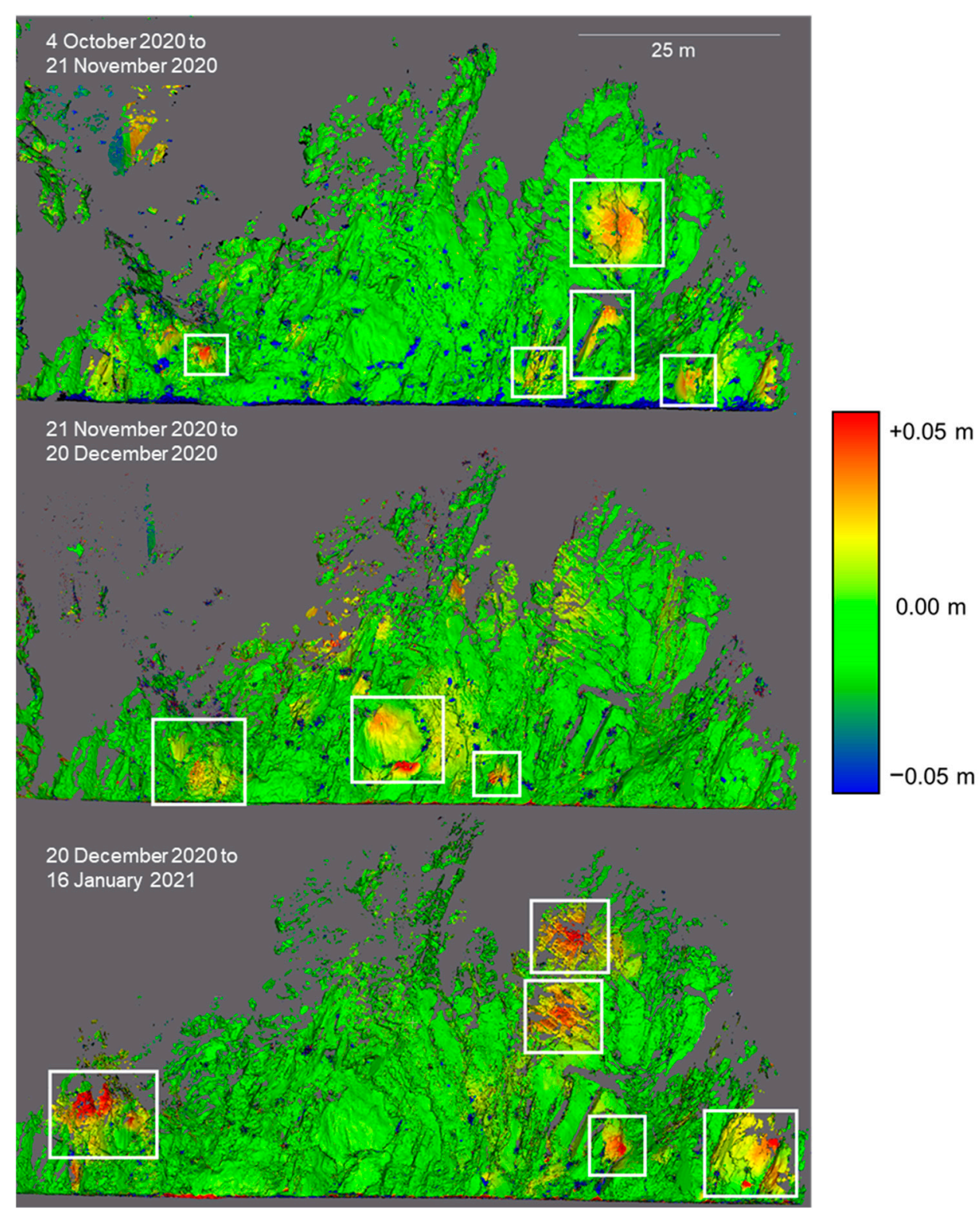

Figure 5. Point clouds for three time steps at Site E, colorized by calculated change. White boxes are areas of anomalous change interpreted to be induced by PUR injection into the slope.

\subsection{Comparison of Pre-and Post-Construction Rockfall and Evaluation of Weather Impacts}

This section compares natural rockfall rates before and after the construction period (Figures 6-11). Comparing monthly totals for April through August in 2020 and 2021 (Figure 6), Site E had similar total rockfall volumes in 2021 compared to 2020 (apart from a single large event in May 2021), but the number of discrete falls each month was higher in 2021. At Site HI, both the volume and number of rockfalls increased post-construction compared to the same months the previous year. The largest natural rockfall observed in the study occurred at Site E in May 2021, as shown in detail in Figure 7. With a calculated volume of almost $1 \mathrm{~m}^{3}$, this rockfall and the surrounding smaller falls occurred during a period of high-intensity rainfall activity in May 2021. 
a)

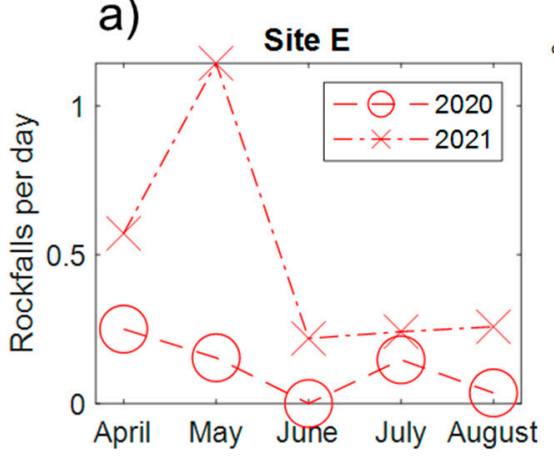

c)

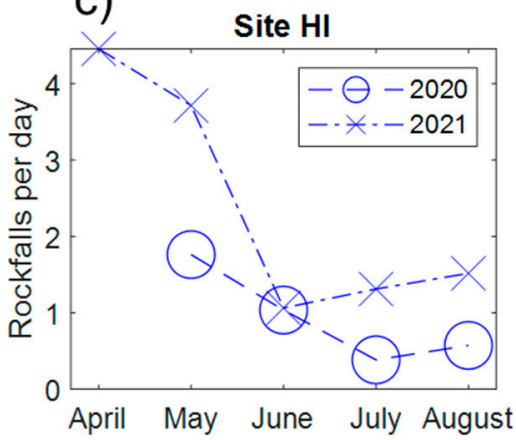

b)

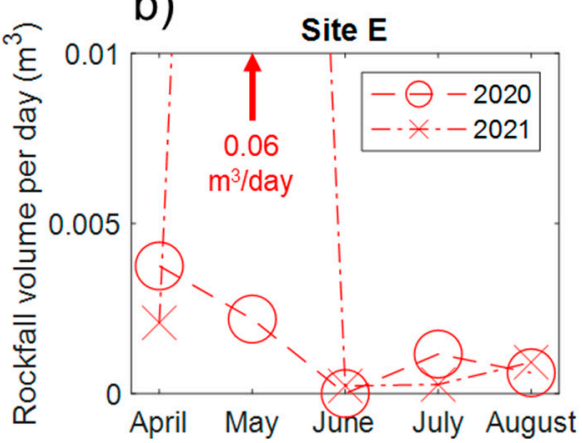

d)

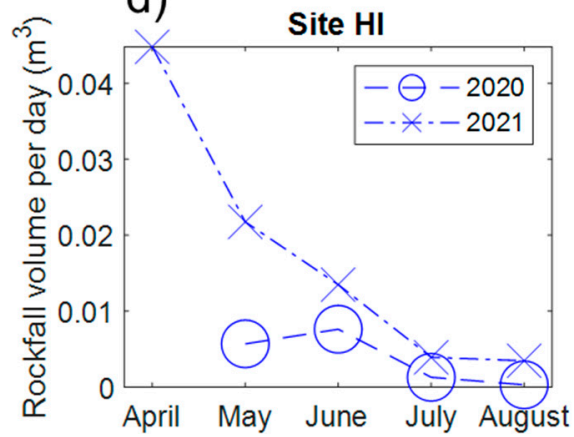

Figure 6. Comparison of monthly number of rockfalls (panels a and $\mathbf{c}$ ) and rockfall volume (panels $\mathbf{b}$ and d) for approximately the same monthly periods in 2020 and 2021 for both sites. Rockfall counts and total volumes were normalized by the number of days in the epoch. The anomalously high rockfall volume for May 2021 (total volume: $1.3 \mathrm{~m}^{3}, 0.06 \mathrm{~m}^{3}$ per day) was omitted to enhance the visibility of the other months.

This general increase in rockfall activity was consistent with an increase in precipitation in 2021 compared to 2020 (Figure 8). In March through May 2021, soon after construction was completed, precipitation in the form of both rain and snowfall increased, and this was matched with a corresponding increase in the number and total volume of rockfalls during those same months. Increased rockfall activity in March 2021 was associated with large snowfall events and frequent freeze-thaw cycles, while rockfall in April and May 2021 was associated with both snow and high-intensity rainstorms.

The frequency distributions of all rockfall volumes were plotted as cumulative frequencymagnitude curves in log-log space in Figure 9. From this plot, we can read, for example, that in summer 2021, there were around eight rockfalls per month with a volume greater than or equal to $0.001 \mathrm{~m}^{3}$. Comparing the 2020 and 2021 curves illustrates that both sites experienced an increase in the frequency of rockfalls and a slight shift towards larger rockfalls in the post-construction period of Summer 2021. The shift to larger volumes, however, was more pronounced for Site HI than for Site E.

The spatial distribution of rockfalls at both sites are illustrated in Figure 10, with different-colored patches representing individual rockfalls and the epoch in which the event occurred. Spatial clustering in the locations of rockfalls was observed at both sites, either due to regions of the rockmass that could be of relatively lower quality, such as the fault zone on the east (right) side of Site HI, or due to progressive rockfall failures, with several distinct but spatially overlapping events. 


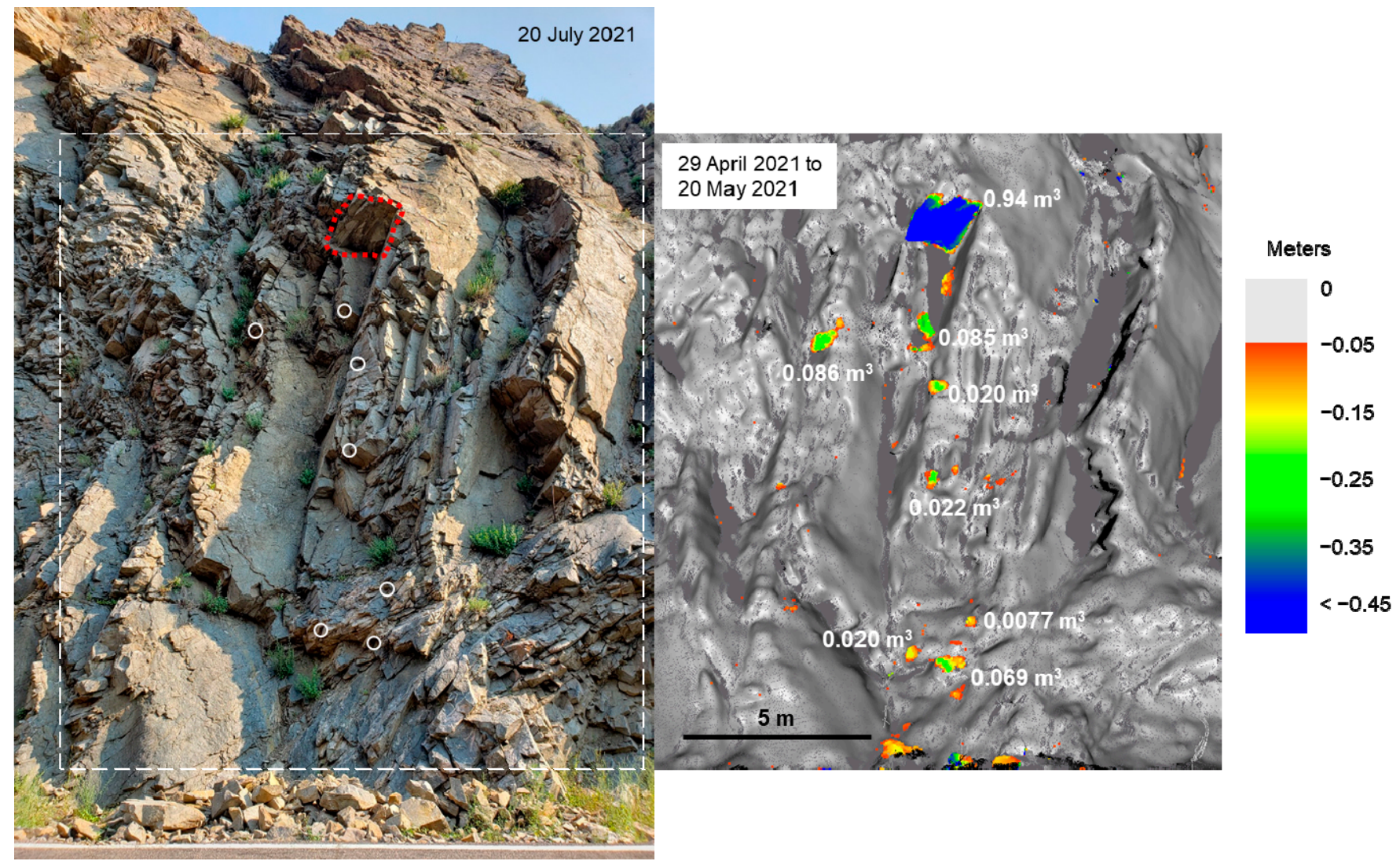

Figure 7. Illustration of a large rockfall at Site E in May 2021. Red dashed area in photograph indicates scar location of the large $0.94 \mathrm{~m}^{3}$ block in the point cloud to the right. White circles indicate locations of other smaller rockfalls. Dashed white box is the approximate extents of the point cloud image shown to the right. Note the road surface visible in the bottom of the left photograph, immediately adjacent to a pile of rockfall debris. Note also that while the limit of detection is set at $0.02 \mathrm{~m}$ in calculations, a gray threshold of $0.05 \mathrm{~m}$ was used in this figure to improve visualization.

Potential correlations between weather and rockfall events are further evaluated in Figure 11. We fit rockfall metrics (count and total volume) to weather metrics (total precipitation and number of freeze-thaw cycles in the epoch) using a single-term exponential function because rockfall phenomena are often distributed log-normally and also because this function fitting resulted in better fit metrics compared to linear fitting [8]. It was observed that both total precipitation in the scanning period and freeze-thaw cycles positively correlated with log-transformed rockfall metrics (total volume and total number of rockfalls in the epoch). The strongest correlations in terms of $R^{2}$ metrics were observed for number of rockfalls vs. precipitation at Site $E\left(R^{2}=0.82\right)$ and number of rockfalls vs. freeze-thaw cycles for Site HI $\left(R^{2}=0.78\right)$. 

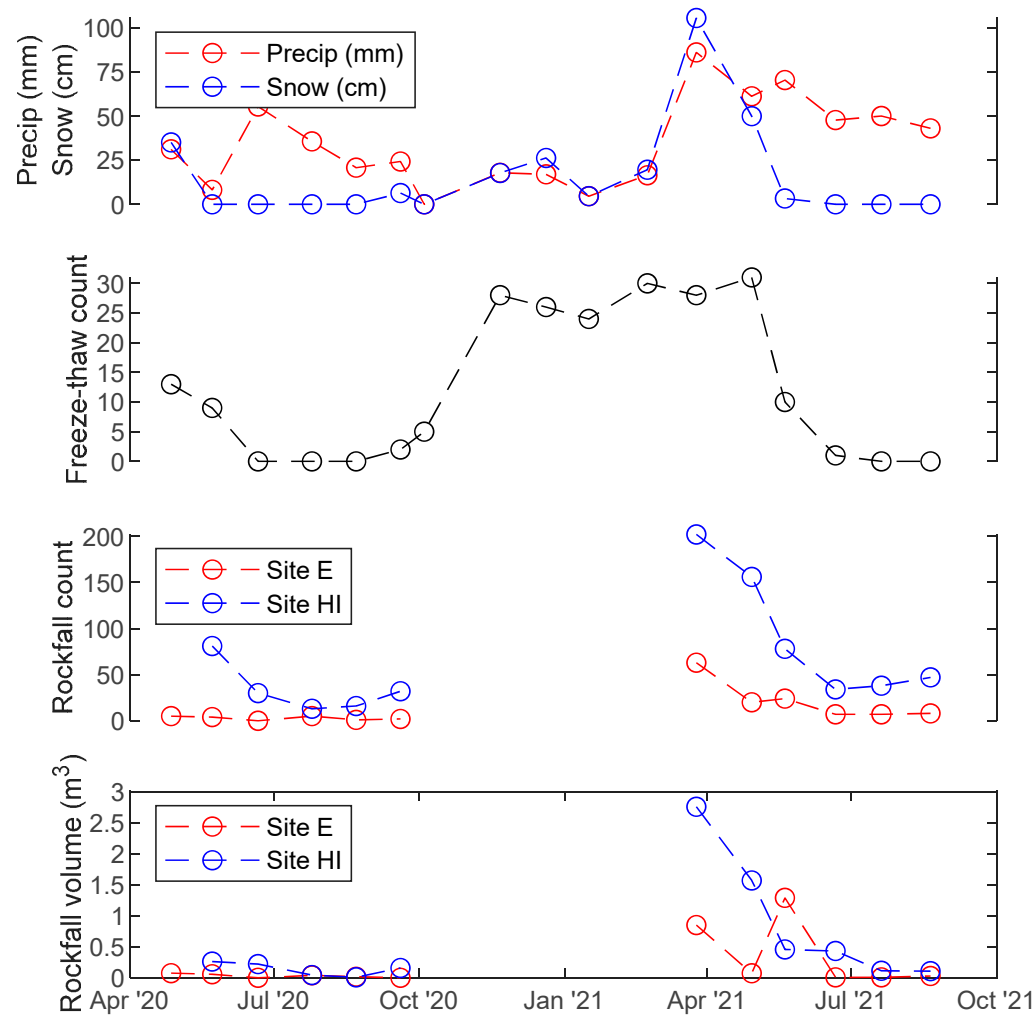

Figure 8. Plots of weather variables, including total precipitation (rain and/or melted snow), snow depth, and number of freeze-thaw cycles, with rockfall metrics per scanning period. Rockfall count and volume are not shown during the construction period of October 2020 to February 2021. Note that total precipitation includes snow-water equivalent, whereas snow is the depth of snowfall only.
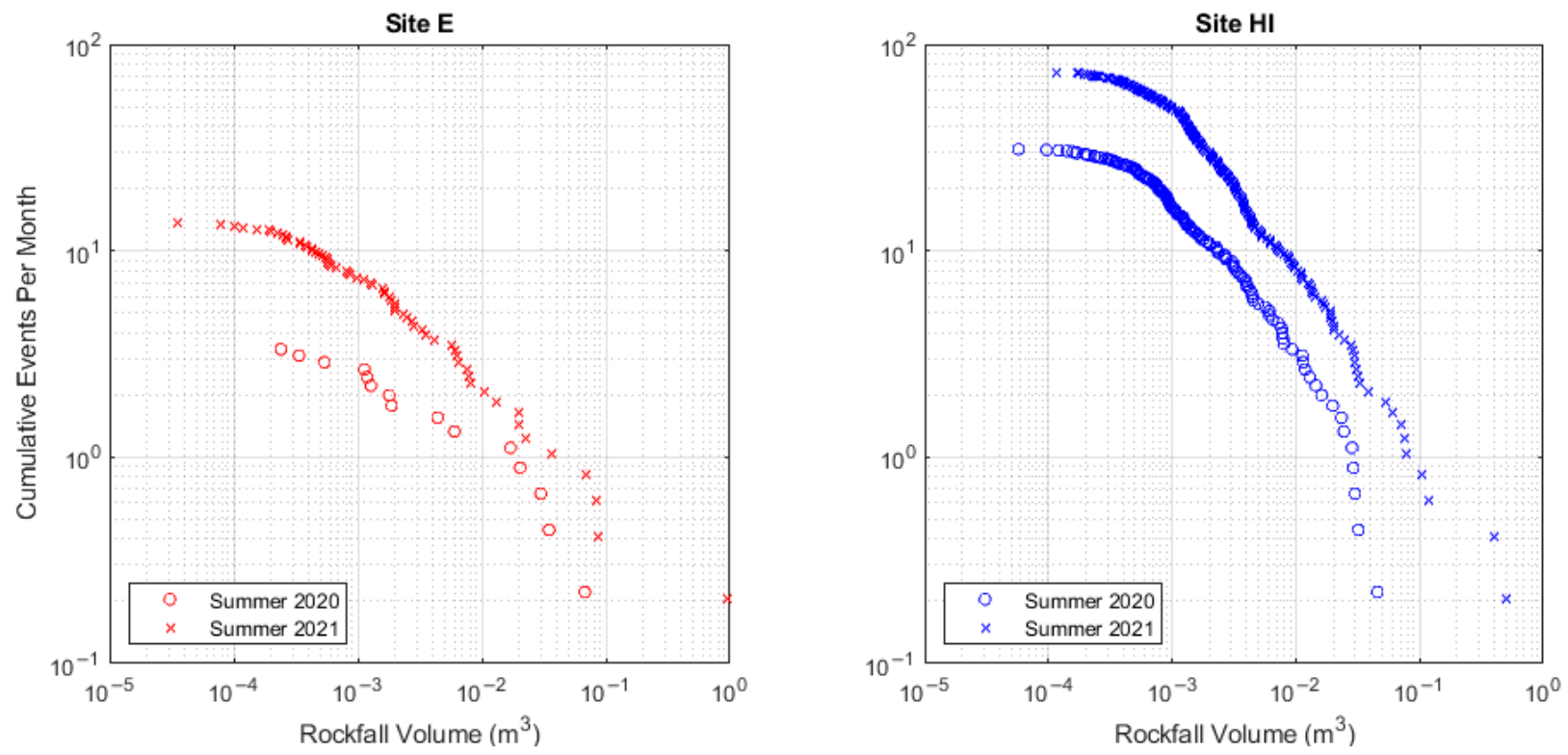

Figure 9. Empirical cumulative rockfall magnitude-frequency plots for Site E (left) and Site HI (right), showing differences in the rockfall size distribution for the April-August period of 2020 and 2021. 

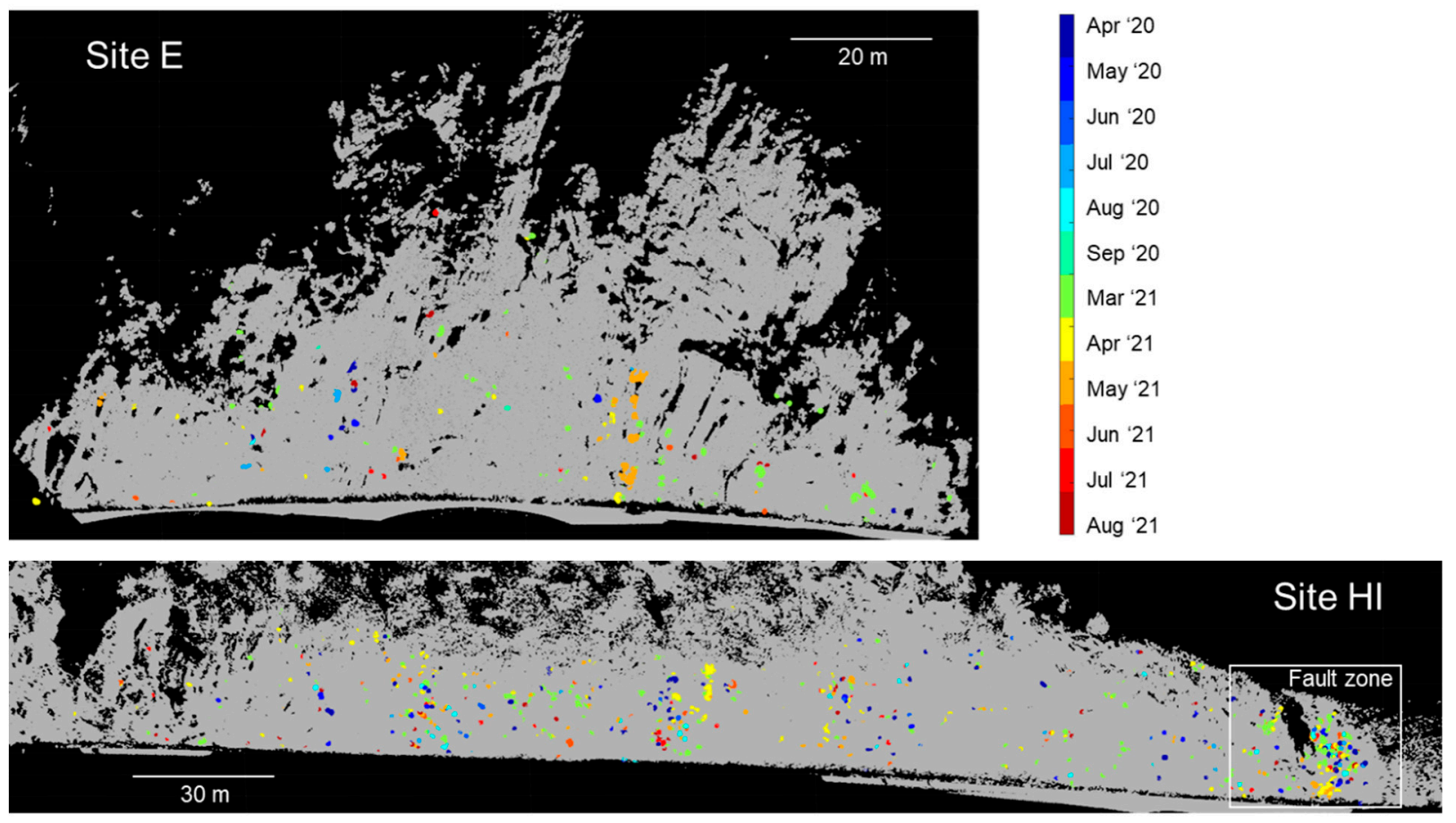

Figure 10. Spatial distribution of rockfall locations during the pre- and post-construction periods for Site E (top) and Site HI (bottom). Rockfalls are indicated by colored patches on the slope, with the specific colors corresponding to the epoch during which the event occurred.
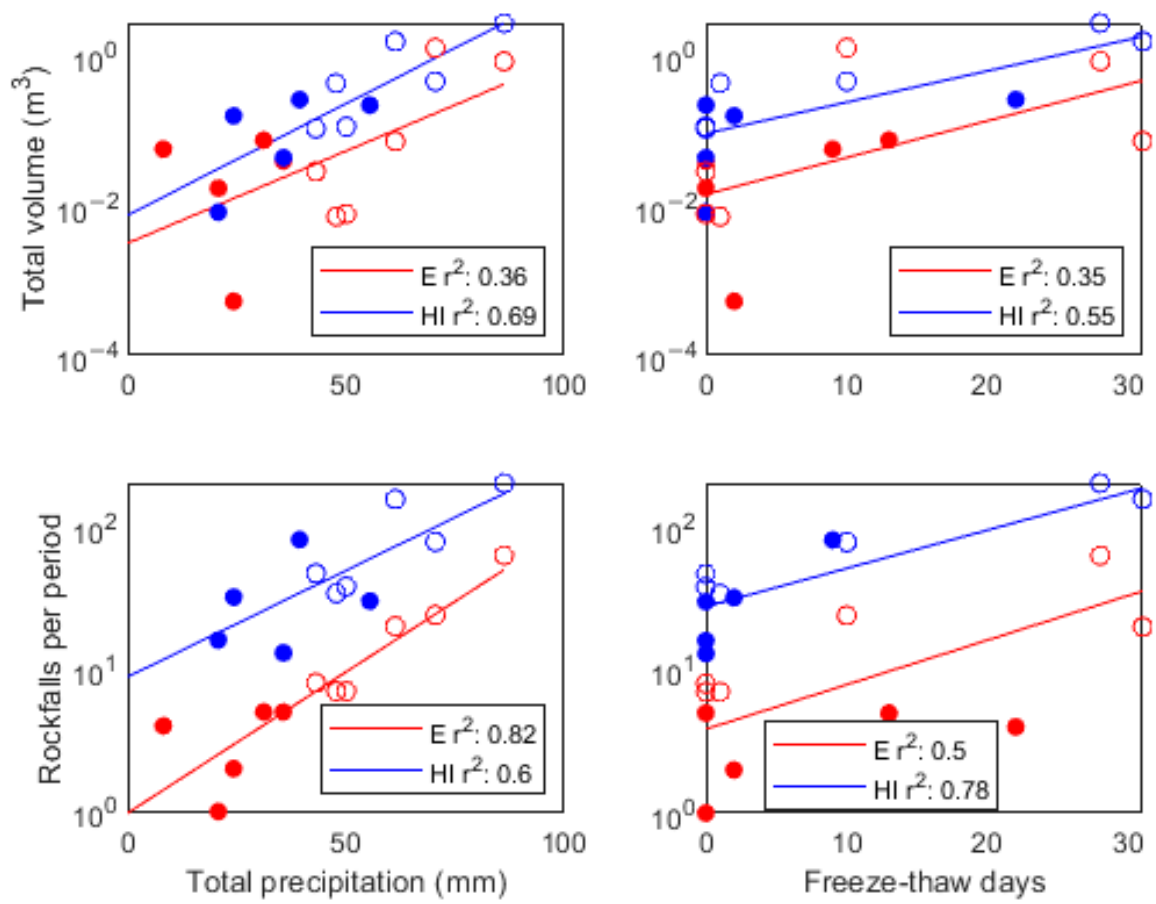

Figure 11. Scatter plots of correlations between number of rockfalls and rockfall volume with total precipitation in the period and the number of freeze-thaw days in the period. Closed circles represent pre-construction data, while open circles represent post-construction data.

\section{Discussion}

The goal of this study was to observe slope changes before, during, and after slope hazard-mitigation strategies were implemented. Our initial hypothesis was that due to removal of a large volume of potentially unstable material and stabilization of potentially mobile blocks, the post-construction rockfall rate should have been greatly reduced 
immediately following construction. We also expected this to be affected minimally by weather variability year-to-year, since scaling was presumed to remove both loose blocks that would normally be destabilized by short-term weather forces and some blocks that are not yet conditioned for failure, ideally improving the condition of the slope. However, the observations did not confirm this. An increase in the rockfall rate was observed immediately post-construction, correlated with above-average spring precipitation. The post-construction summer rockfall rate continued to be slightly elevated compared to the previous summer, despite similar precipitation totals for the months of June and July for both years.

There are several possible, non-mutually exclusive explanations for the observed increase in rockfall:

1. The disturbance caused by construction activities could result in a post-construction period of increased rockfall activity as the slope adjusts to a new equilibrium condition, and the adjustment period could be perhaps several months to years.

2. Mitigation could have the largest impact on the rate of large rockfalls in areas that were reinforced with bolts and PUR and a relatively small impact on the rate of smaller rockfalls that are typically destabilized annually by weather events.

3. While scaling and reinforcement could moderately improve slope condition and reduce the number of unstable blocks, it may be a small improvement relative to the influence of conditioning/triggering forces of freeze-thaw and precipitation, such that the "signal" of mitigation is lost in the "noise" of weather-triggered rockfalls.

4. It may be the case that rockfalls of the range of sizes observed in this study were conditioned for failure over a relatively short antecedent period of a few weeks or months (as observed by [8] for another crystalline rock slope in Colorado), meaning that mechanical scaling performed in September and October could have very little influence on the occurrence of relatively small rockfalls three or more months later.

5. The rockmass could be poor enough quality that the newly exposed rock surface was just as fractured and weathered as the old surface, meaning that the number of unstable blocks could be essentially unchanged by scaling and reinforcement.

Recent literature on the triggering and conditioning of rockfalls around the world supports explanations 3 and 4 . Studies on the relationships between rockfall and weather typically only considered antecedent periods of less than five days $[3,5,7,8,38]$. In contrast, Schovanec [8] searched for correlations between rockfall and weather for antecedent periods of up to one year. However, it was still concluded in this case that the most likely triggering and conditioning periods were no more than two months prior to the event in winter and no more than one month prior in summer. This suggests that rockfalls of this volume range are generally conditioned over relatively short periods. As a result, a slope that was mechanically scaled could reasonably return to its natural equilibrium state, with no memory of the scaling of small rockfalls, over a single winter season. This is further supported by the observed rockfall rate at Site $\mathrm{HI}$ in the fault zone on the easternmost end of the slope. This zone of weak rock was scaled in fall 2020 (far right of Figure 4), but the rockfall rate continued to be high in this area after construction was completed (far right of Figure 10). However, the memory of larger, more hazardous blocks that are less commonly observed may be longer.

If the above explanation is correct, a potential implication of this work is that mechanical scaling may not be effective in reducing the occurrence of small- to medium-sized rockfalls $\left(<1 \mathrm{~m}^{3}\right)$ at these sites, even for short time scales of less than one year. However, other mitigation activities targeted at blocks larger than $1 \mathrm{~m}^{3}$, such as spot bolting, may still have been effective in reducing the hazard. At Site HI, for example, the overall risk was effectively reduced by increasing the size of the catchment ditch and installing a concrete barrier. This effectively eliminated the risk of small rockfalls at this location. In contrast, at Site $\mathrm{E}$, the narrowness of the right-of-way precluded any modification of the traffic pattern or widening of the ditch. In this case, PUR injection and spot bolting were used with the goal of stabilizing the rockmass, which would likely only have a significant influence on 
larger rockfalls. As our observations show, small rockfalls $\left(<1 \mathrm{~m}^{3}\right)$ were still able to reach the road surface post-mitigation.

It is evident from Figure 6 that in March 2021, snowfall combined with freeze-thaw cycles was likely the dominant trigger of rockfall, while in May 2021, frequent high-intensity rainstorms were a more likely trigger. These conditions can act independently or in combination as both conditioning factors (longer term) and triggering factors (short term) responsible for a failure, making it challenging to construct a comprehensive explanation for the cause of a particular event. While a full analysis of weather and climate correlations was beyond the scope of this work, the preliminary results presented here were consistent with those of Schovanec [8], who found that freeze-thaw and precipitation played complementary roles in promoting and triggering rockfalls throughout the year.

\section{Conclusions}

Slope mitigation is a commonly used approach to reduce rockfall risks in mountainous areas. This study used TLS to record rockfall occurring on two slopes in western Colorado before, during, and after slope construction was performed, with mechanical scaling and PUR injection being the major activities. While we initially expected rockfall rates to be reduced post-construction, we instead observed an increase in rockfall, strongly correlated with precipitation and freeze-thaw triggering events. Several explanations were proposed for this unexpected result, but it is ultimately necessary to collect more data over several years' worth of seasonal cycles to draw more firm conclusions.

Regardless, this study demonstrates the utility of terrestrial laser scanning in evaluating slope-mitigation measures in an objective way. With this technology available, owners and engineers no longer need to be reliant on anecdotal, potentially spurious evidence of mitigation effectiveness. Regular imaging of slopes and comparison with weather and climate data can also be used to construct statistical models of rockfall triggering, potentially enabling rockfall forecasting over weekly or monthly timescales. Although the relationship between natural hazards and climate change is complex [39,40], the findings presented in this study and future data collection could also contribute to a greater understanding of how rockfall hazards could change in Colorado in the future.

A potential limitation of TLS monitoring in this context is that it is often much more challenging to set up these systems for high-frequency (e.g., daily) monitoring than a camera system, but high temporal frequency is needed to be able to precisely identify the timing and triggering conditions of individual failures [13]. Future work could make use of permanent camera systems (e.g., $[14,41])$ to better constrain the time of failure and further improve our ability to forecast potentially dangerous rockfall events.

Author Contributions: Conceptualization, G.W.; Data curation, L.W.; Formal analysis, L.W.; Funding acquisition, G.W.; Investigation, L.W.; Methodology, L.W. and G.W.; Writing-original draft, L.W.; Writing-review \& editing, G.W. All authors have read and agreed to the published version of the manuscript.

Funding: This research was funded by the Colorado Department of Transportation.

Data Availability Statement: Rockfall statistics and summary data will be provided upon request.

Acknowledgments: We would like to thank the Colorado Department of Transportation for providing funding for this research. We would also like to thank David Bonneau for graciously sharing his code for the alphaSolid function. Thanks also to those who assisted with data collection, including Cameron Phillips, Brian Gray, Adam Malsam, Mark Weidner, and Heather Schovanec.

Conflicts of Interest: The authors declare no conflict of interest. 


\section{References}

1. Kromer, R.; Rowe, E.; Hutchinson, J.; Lato, M.; Abellán, A. Rockfall risk management using a pre-failure deformation database. Landslides 2018, 15, 847-858. [CrossRef]

2. Wyllie, D.C.; Mah, C. Rock Slope Engineering: Fourth Edition; CRC Press: Boca Raton, FL, USA, 2004. ISBN 978-0-415-28000-6.

3. Macciotta, R.; Martin, C.D.; Edwards, T.; Cruden, D.M.; Keegan, T. Quantifying weather conditions for rock fall hazard management. Georisk Assess. Manag. Risk Eng. Syst. Geohazards 2015, 9, 171-186. [CrossRef]

4. Ravanel, L.; Deline, P. Rockfall Hazard in the Mont Blanc Massif Increased by the Current Atmospheric Warming. In Engineering Geology for Society and Territory_Volume 1; Lollino, G., Manconi, A., Clague, J., Shan, W., Chiarle, M., Eds.; Springer International Publishing: Cham, Switzerland, 2015; pp. 425-428.

5. D'Amato, J.; Hantz, D.; Guerin, A.; Jaboyedoff, M.; Baillet, L.; Mariscal, A. Influence of meteorological factors on rockfall occurrence in a middle mountain limestone cliff. Nat. Hazards Earth Syst. Sci. 2016, 16, 719-735. [CrossRef]

6. Kanari, M.; Katz, O.; Weinberger, R.; Porat, N.; Marco, S. Evaluating earthquake-induced rockfall hazard near the Dead Sea Transform. Nat. Hazards Earth Syst. Sci. 2019, 19, 889-906. [CrossRef]

7. Matsuoka, N. A multi-method monitoring of timing, magnitude and origin of rockfall activity in the Japanese Alps. Geomorphology 2019, 336, 65-76. [CrossRef]

8. Schovanec, H.E. Development of Semi-Automated Lidar Processing Algorithms to Correlate Climate Variables to Rockfall Patterns for a Slope Near Glenwood Springs, Colorado; Text, Colorado School of Mines: Golden, CO, USA, 2020.

9. Crosta, G.B.; Agliardi, F.; Frattini, P.; Lari, S. Key Issues in Rock Fall Modeling, Hazard and Risk Assessment for Rockfall Protection. In Engineering Geology for Society and Territory_Volume 2; Lollino, G., Giordan, D., Crosta, G.B., Corominas, J., Azzam, R., Wasowski, J., Sciarra, N., Eds.; Springer International Publishing: Cham, Switzerland, 2015; pp. $43-58$.

10. Toe, D.; Mentani, A.; Govoni, L.; Bourrier, F.; Gottardi, G.; Lambert, S. Introducing Meta-models for a More Efficient Hazard Mitigation Strategy with Rockfall Protection Barriers. Rock Mech. Rock Eng. 2018, 51, 1097-1109. [CrossRef]

11. Hutchison, B.J.; Chambers, J. Monitoring of Structurally Controlled Deformations at the Kanmantoo Copper Mine; Australian Centre for Geomechanics: Perth, Australia, 2020; pp. 1495-1506.

12. Hutchison, B.J.; Morrison, A.T.; Lucas, D.S. Steep Wall Mining: Engineered Structures Used in the Management of Rockfall Hazards at Kanmantoo Copper Mine; Australian Centre for Geomechanics: Perth, Australia, 2020; pp. 831-848.

13. Williams, J.G.; Rosser, N.J.; Hardy, R.J.; Brain, M.J.; Afana, A.A. Optimising 4-D surface change detection: An approach for capturing rockfall magnitude-frequency. Earth Surf. Dyn. 2018, 6, 101-119. [CrossRef]

14. Kromer, R.; Walton, G.; Gray, B.; Lato, M.; Group, R. Development and Optimization of an Automated Fixed-Location Time Lapse Photogrammetric Rock Slope Monitoring System. Remote Sens. 2019, 11, 1890. [CrossRef]

15. Anders, K.; Winiwarter, L.; Lindenbergh, R.; Williams, J.G.; Vos, S.E.; Höfle, B. 4D objects-by-change: Spatiotemporal segmentation of geomorphic surface change from LiDAR time series. ISPRS J. Photogramm. Remote Sens. 2020, 159, 352-363. [CrossRef]

16. Telling, J.; Lyda, A.; Hartzell, P.; Glennie, C. Review of Earth science research using terrestrial laser scanning. Earth-Sci. Rev. 2017, 169, 35-68. [CrossRef]

17. Bonneau, D.; DiFrancesco, P.-M.; Hutchinson, D.J. Surface Reconstruction for Three-Dimensional Rockfall Volumetric Analysis. ISPRS Int. J. Geo-Inf. 2019, 8, 548. [CrossRef]

18. Weidner, L.; Walton, G.; Kromer, R. Classification methods for point clouds in rock slope monitoring: A novel machine learning approach and comparative analysis. Eng. Geol. 2019, 263, 105326. [CrossRef]

19. Weidner, L.; Walton, G.; Krajnovich, A. Classifying rock slope materials in photogrammetric point clouds using robust color and geometric features. ISPRS J. Photogramm. Remote Sens. 2021, 176, 15-29. [CrossRef]

20. DiFrancesco, P.-M.; Bonneau, D.; Hutchinson, D.J. The Implications of M3C2 Projection Diameter on 3D Semi-Automated Rockfall Extraction from Sequential Terrestrial Laser Scanning Point Clouds. Remote Sens. 2020, 12, 1885. [CrossRef]

21. Schovanec, H.; Walton, G.; Kromer, R.; Malsam, A. Development of Improved Semi-Automated Processing Algorithms for the Creation of Rockfall Databases. Remote Sens. 2021, 13, 1479. [CrossRef]

22. Carrea, D.; Abellan, A.; Derron, M.-H.; Gauvin, N.; Jaboyedoff, M. MATLAB Virtual Toolbox for Retrospective Rockfall Source Detection and Volume Estimation Using 3D Point Clouds: A Case Study of a Subalpine Molasse Cliff. Geosciences 2021, 11, 75. [CrossRef]

23. Marinos, V.; Marinos, P.; Hoek, E. The geological strength index: Applications and limitations. Bull. Eng. Geol. Environ. 2005, 64, 55-65. [CrossRef]

24. Hoek, E.; Brown, E.T. Practical estimates of rock mass strength. Int. J. Rock Mech. Min. Sci. 1997, 34, 1165-1186. [CrossRef]

25. Lienhart, D.A. The Geographic Distribution of Intensity and Frequency of Freeze-Thaw Cycles. Environ. Eng. Geosci. 1988, 25, 465-469. [CrossRef]

26. DeMarco, M.J. Polyurethane Resin (PUR) Injection for Rock Mass and Structure Stabilization. In Proceedings of the International Conference on Case Histories in Geotechnical Engineering, Arlington, VA, USA, 11-16 August 2008; Paper No. 7.07a.

27. Abellán, A.; Oppikofer, T.; Jaboyedoff, M.; Rosser, N.J.; Lim, M.; Lato, M.J. Terrestrial laser scanning of rock slope instabilities. Earth Surf. Process. Landf. 2014, 39, 80-97. [CrossRef]

28. Kromer, R.; Abellán, A.; Hutchinson, D.; Lato, M.; Edwards, T.; Jaboyedoff, M. A 4D Filtering and Calibration Technique for Small-Scale Point Cloud Change Detection with a Terrestrial Laser Scanner. Remote Sens. 2015, 7, 13029-13052. [CrossRef] 
29. van Veen, M.; Hutchinson, D.J.; Kromer, R.; Lato, M.; Edwards, T. Effects of sampling interval on the frequency-Magnitude relationship of rockfalls detected from terrestrial laser scanning using semi-automated methods. Landslides 2017, 14, 1579-1592. [CrossRef]

30. CloudCompare. Cloudcompare.org, Version 2.12. 2021. Available online: https:/ / cloudcompare.org (accessed on 21 July 2021$)$

31. Farmakis, I.; Bonneau, D.; Hutchinson, D.J.; Vlachopoulos, N. Targeted Rock Slope Assessment Using Voxels and Object-Oriented Classification. Remote Sens. 2021, 13, 1354. [CrossRef]

32. Lague, D.; Brodu, N.; Leroux, J. Accurate 3D comparison of complex topography with terrestrial laser scanner: Application to the Rangitikei canyon (N-Z). ISPRS J. Photogramm. Remote Sens. 2013, 82, 10-26. [CrossRef]

33. Winiwarter, L.; Anders, K.; Höfle, B. M3C2-EP: Pushing the limits of 3D topographic point cloud change detection by error propagation. ISPRS J. Photogramm. Remote Sens. 2021, 178, 240-258. [CrossRef]

34. Ester, M.; Kriegel, H.-P.; Sander, J.; Xu, X. A Density-Based Algorithm for Discovering Clusters in Large Spatial Databases with Noise. In Proceedings of the Second International Conference on Knowledge Discovery and Data Mining (KDD-96), Portland, OR, USA, 2-4 August 1996; AAAI Press: Palo Alto, CA, USA, 1996; pp. 226-231.

35. Carrea, D.; Abellan, A.; Derron, M.-H.; Jaboyedoff, M. Automatic Rockfalls Volume Estimation Based on Terrestrial Laser Scanning Data. In Engineering Geology for Society and Territory_Volume 2; Lollino, G., Giordan, D., Crosta, G.B., Corominas, J., Azzam, R., Wasowski, J., Sciarra, N., Eds.; Springer International Publishing: Cham, Switzerland, 2015; pp. 425-428.

36. Zoumpekas, T.; Puig, A.; Salamó, M.; García-Sellés, D.; Nuñez, L.B.; Guinau, M. An intelligent framework for end-to-end rockfall detection. Int. J. Intell. Syst. 2021, 36, 6471-6502. [CrossRef]

37. Edelsbrunner, H.; Mücke, E.P. Three-dimensional alpha shapes. ACM Trans. Graph. 1994, 13, 43-72. [CrossRef]

38. Delonca, A.; Gunzburger, Y.; Verdel, T. Statistical correlation between meteorological and rockfall databases. Nat. Hazards Earth Syst. Sci. 2014, 14, 1953-1964. [CrossRef]

39. Allen, S.; Huggel, C. Extremely warm temperatures as a potential cause of recent high mountain rockfall. Glob. Planet. Change 2013, 107, 59-69. [CrossRef]

40. Gariano, S.L.; Guzzetti, F. Landslides in a changing climate. Earth-Sci. Rev. 2016, 162, 227-252. [CrossRef]

41. Blanch, X.; Abellán, A.; Guinau, M. Rockfall Monitoring at a High-Temporal Rate Using Cost-Effective Photogrammetric Systems. In Proceedings of the Geophysical Research Abstracts; Copernicus Publications: Vienna, Austria, 2019; Volume 21, Available online: https: / / ui.adsabs.harvard.edu/abs/2019EGUGA..2111591B (accessed on 21 July 2021). 